\title{
Myelography in the Age of MRI: Why We Do It, and How We Do It
}

\author{
Christoph Ozdoba, ${ }^{1}$ Jan Gralla, ${ }^{1}$ Alexander Rieke, ${ }^{1}$ Ralph Binggeli, ${ }^{2}$ and Gerhard Schroth ${ }^{1}$ \\ ${ }^{1}$ University Institute of Diagnostic and Interventional Neuroradiology, Inselspital, University of Bern, Freiburgstrasse 4, \\ 3010 Bern, Switzerland \\ ${ }^{2}$ Department of Neurosurgery, Inselspital, University of Bern, 3010 Bern, Switzerland
}

Correspondence should be addressed to Christoph Ozdoba, christoph.ozdoba@insel.ch

Received 16 August 2010; Accepted 17 January 2011

Academic Editor: Carlo Masciocchi

Copyright ( $) 2011$ Christoph Ozdoba et al. This is an open access article distributed under the Creative Commons Attribution License, which permits unrestricted use, distribution, and reproduction in any medium, provided the original work is properly cited.

\begin{abstract}
Myelography is a nearly ninety-year-old method that has undergone a steady development from the introduction of water-soluble contrast agents to CT myelography. Since the introduction of magnetic resonance imaging into clinical routine in the mid-1980s, the role of myelography seemed to be constantly less important in spinal diagnostics, but it remains a method that is probably even superior to MRI for special clinical issues. This paper briefly summarizes the historical development of myelography, describes the technique, and discusses current indications like the detection of CSF leaks or cervical root avulsion.
\end{abstract}

\section{Introduction}

The method that we know as "myelography" was first described by Sicard and Forestier [1] in 1921; by the end of the 1920s, it had become an established technique [2,3]. In 1944, iodized oil (Lipiodol) was replaced by Iophendylate (Pantopaque) [4] as contrast agent for intrathecal application, but still, the procedure remained elaborate: the contrast agent that was applied by an intrathecal injection had to be withdrawn by suction at the end of the procedure, and the contrast agent itself was not free of adverse reactions $[5,6]$. Yet, for decades myelography was the only diagnostic method that allowed to obtain information about soft-tissue structures in the spinal canal. Disc herniation, narrowing of the dural sac due to hemorrhage or tumor as well as expansion by intramedullary tumor, and nerve root compression that were not visible on conventional X-ray could be visualized.

In the seventies and eighties, the introduction of computed tomography and water-soluble nonionic contrast agents made the procedure easier to perform, safer and diagnostically more precise. Myelo-CT was first published in 1976 by Di Chiro and Schellinger [7], and it soon became a standard procedure.

Then, MR imaging found its way into clinical routine, and over a period of just some years, it made myelography look obsolete. A search for "myelography" in combination with "computed tomography" and/or "magnetic resonance" on PubMed yielded the results listed in Table 1 for the last six decades; according to these data, myelography's best years were obviously over at the end of the 1980s. It seemed that the method was on the same way that pneumencephalography had gone two decades before: from clinical routine into the archives of the history of medicine. Gradually, however, radiologists and clinicians realized that $\mathrm{MR}$, although superior in many aspects, could not answer all questions related to spinal pathology.

Today, myelography is still established as a safe method [8] for some special clinical issues. The aim of this brief paper is to share our experience-which is based on about 6,000 myelographies in the last 17 years-regarding procedural aspects and instrumentation and to discuss the indications where myelography has remained the method of choice even in the early 21 st century.

\section{Myelography: How Do We Do It?}

In many cases, patients scheduled for a myelography already have previous imaging studies; these are examined by the performing physician before the procedure to study the individual anatomy (e.g., scoliosis, Baastrup) and to select 
TAble 1: Results of a PubMed search for "myelography" alone and in combination with "computed tomography" and/or "magnetic resonance".

\begin{tabular}{|c|c|c|c|c|}
\hline Publication date from—-to & $\begin{array}{l}\text { Citations containing } \\
\text { "myelography" }\end{array}$ & $\begin{array}{l}\text { Citations containing } \\
\text { "myelography" and } \\
\text { "computed tomography" }\end{array}$ & $\begin{array}{l}\text { Citations containing } \\
\text { "myelography" and } \\
\text { "magnetic resonance" }\end{array}$ & $\begin{array}{l}\text { Citations containing } \\
\text { "myelography" and } \\
\text { "computed tomography" } \\
\text { and "magnetic resonance" }\end{array}$ \\
\hline 1950-1959 & 202 & - & - & - \\
\hline 1960-1969 & 1051 & - & - & - \\
\hline 1970-1979 & 2183 & 81 & - & - \\
\hline 1980-1989 & 3226 & 1385 & 363 & 243 \\
\hline 1990-1999 & 1902 & 896 & 865 & 507 \\
\hline 2000-2009 & 987 & 191 & 579 & 121 \\
\hline
\end{tabular}

Source: U.S. National Library of Medicine/National Institutes of Health (http://www.ncbi.nlm.nih.gov/pubmed).

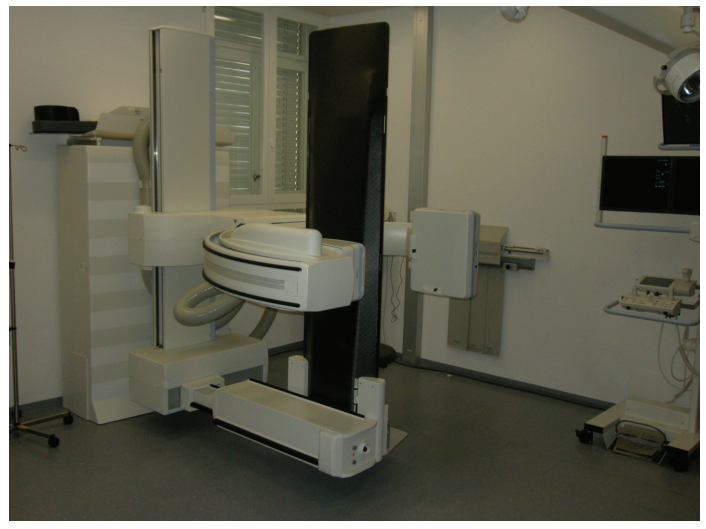

Figure 1: The myelography workplace. The table is tiltable by more than $90^{\circ}$ so that a head-down position can be achieved.

the most appropriate level for the puncture. The procedure should be performed with the lowest possible radiation exposure; this requires state-of-the-art fluoroscopic equipment. We use a Siemens Artis Multi-Purpose system (Siemens Medical Systems, Erlangen, Germany) with a fully tiltable patient couch (Figure 1). The puncture is performed with the patient in an upright position, that is, sitting on a specially designed chair; patients are instructed to form "a cat's arched back" (Figure 2).

This is not in accordance with the guidelines for myelography jointly defined by the American College of Radiology and the American Society of Neuroradiology [9] that suggest a prone position; in our experience, however, sitting for just some minutes (with support, if necessary) is possible for most patients, and it vastly simplifies the lumbar puncture. The rounded back makes sure that the spinous processes in the lumbar spine are distracted as far as possible.

We usually perform the spinal tap at lumbar level $2 / 3$; this ensures that we do not accidentally puncture the conus, and it is just above the clinically most often affected segments so that we avoid a puncture into a herniated disc. Standard for the puncture is a $20 \mathrm{G}(0.9 \mathrm{~mm}) 90 \mathrm{~mm}$ Quincke needle (Pic Indolor, Artsana S.p.A., Grandate, Italy).

In routine procedures, $5-10 \mathrm{ml} \mathrm{CSF}$ are taken for laboratory studies. Then, the contrast agent (Iopamiro (lumbar:

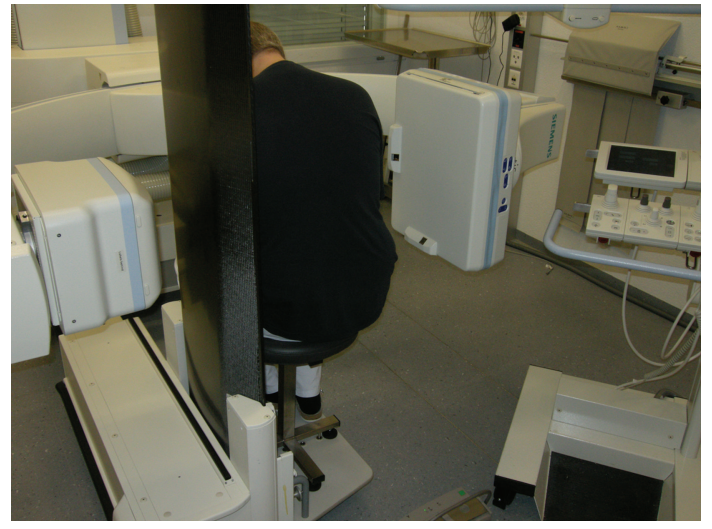

Figure 2: Volunteer demonstrating the patient position for the lumbar tap.

200 and 300, $10 \mathrm{ml}$ each; cervical: 300, $20 \mathrm{ml}$ ), Bracco, Milan, Italy) is injected under fluoroscopic control. This allows to immediately identify and correct accidental injections into the epidural space and to check whether the contrast flow is obstructed. A picture with the needle in situ is taken for documentation, then, the needle is removed. The patient couch is rotated to a horizontal position with the patient still in a "sitting" position on the chair.

For lumbar myelography, contrast filling should reach up to the thoracic level D10 so that the conus is included. The special chair is then removed, the patient turned in the prone position on the stomach and dural sac and root filling are documented in strict a.p.-view and by rotating the C-arch so that the lumbar roots are optimally visualized, that is, about $25^{\circ}$ lateral in each direction (Figure 3 ).

Then, the table is tilted so that the patient gets into an upright (standing) position. The a.p. and oblique shots are repeated and functional pictures in flexion and extension are taken. The ACR/ASNR guidelines do not mention these additional projections; in our experience, however, they may be the diagnostically most relevant of the study (Figure 4). The whole procedure does not take more than five minutes for an experienced team.

For cervical myelography which we only perform ascending via lumbar puncture for safety reasons, it is important 


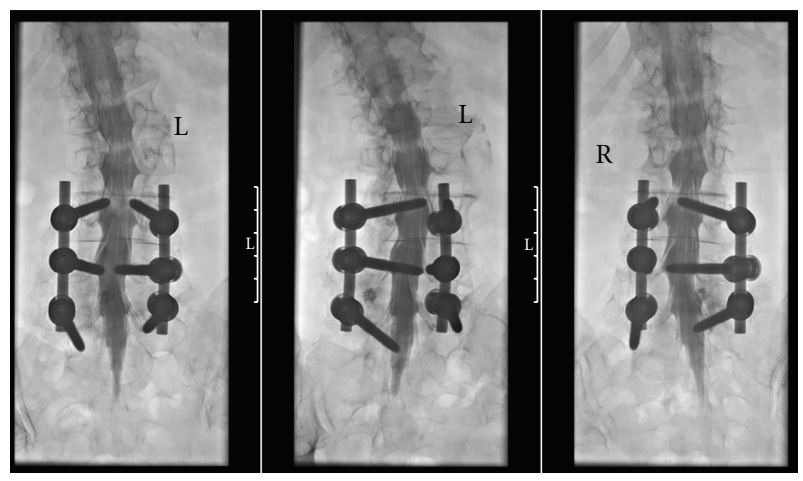

Figure 3: Standard projections in prone position. From left to right: a.p., about $25^{\circ}$ left and right to show the lumbar nerve roots. Taking these images under fluoroscopic control makes sure that even with stabilizing material on three levels the roots are visible from their origin to the foramen.

to instruct the patient to keep the head reclined during the contrast injection, that is, while still lying on the side. This ensures that the contrast agent does not enter the intracranial CSF spaces. It is usually necessary to tilt the patient couch head down by $10-15^{\circ}$ to pass the thoracic spine. Again, the upwards contrast flow is followed by fluoroscopy. When contrast has reached the lower part of the cervical spine, the patient is turned on the stomach. This rotation should be done by the team, not by the patient himself, to avoid excessive motion that might drive the contrast column unwantedly far upwards. The patient's head must remain reclined. With the patient in the prone position lying on the stomach, a.p. and oblique views are taken (Figure 5).

\section{Myelography: When Do We Do It?}

The majority of patients at our institution are referred for myelography by orthopedic surgeons and neurosurgeons. Table 2 and Figure 6 show that today, the total number of these procedures is less than $45 \%$ of what it was ten years ago.

Aside from patients where MR imaging is not possible for safety reasons (e.g., pacemaker), severe image quality degradation due to metallic implants, claustrophobia, or in cases where kyphoscoliosis makes image acquisition and interpretation extremely difficult, however, there are still indications for myelography as an independent diagnostic tool.

MRI seems to be the ideal tool for spinal imaging as it has some obvious advantages over myelography/myelo-CT: no lumbar puncture, no X-ray exposition, no intrathecal contrast agents, excellent soft-tissue contrast.

Modern MRI, however, is not automatically superior to "old-fashioned" myelography: Bartynski and Lin [10] have shown that nerve root compression in the lateral recess is underestimated by MRI in nearly $30 \%$ of surgically confirmed cases compared to only 5 to $7 \%$ in myelography. While a study published in 2005 [11] saw no difference in the diagnostic and predictive value of myelography, myelo-CT

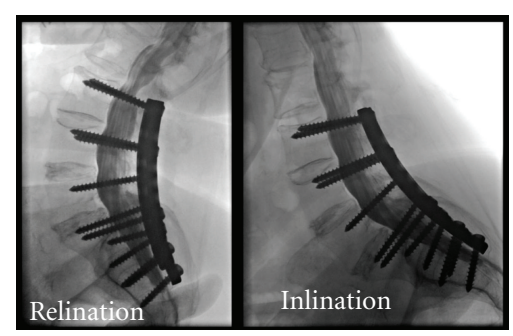

(a)

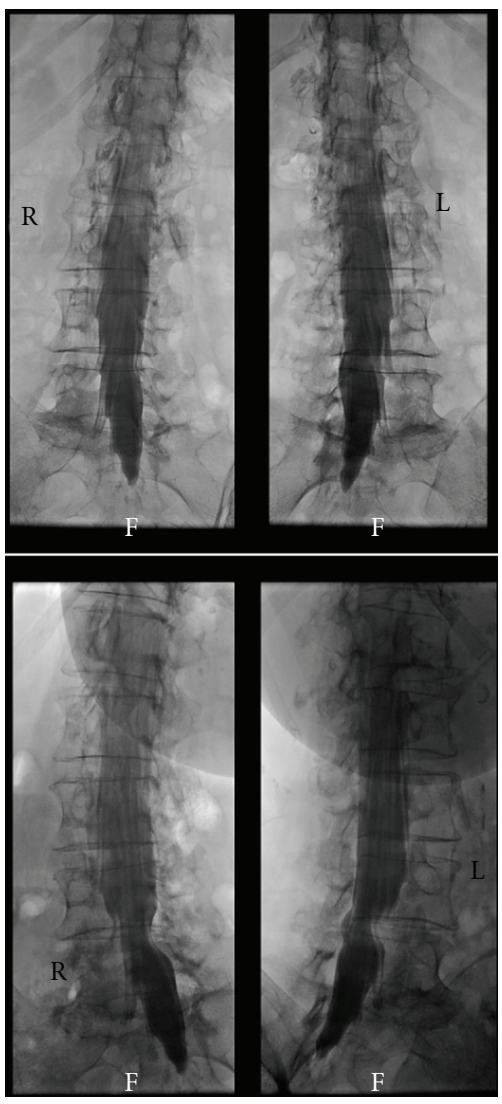

(b)

FIGURE 4: Diagnostic value of additional upright/functional views. (a) Extension (left) shows marked narrowing of the sagittal dural sac diameter directly above the stabilization. The finding in flexed position (right) is normal. This information cannot be obtained in the prone position alone. (b) Oblique views, top: prone position, bottom: patient standing upright. Shortening of the left L4 root and compression of the left L5 origin are only visible in the upright position.

and MRI in cases of severe spinal stenosis, a recent Japanese study [12] found myelography with CT myelography "more reliable and reproducible than MRI" when deciding on which levels decompressive lumbar surgery should be performed. Furthermore, and especially important in cases where surgery is discussed, MRI tends to underestimate the width of the spinal canal and the foramina, thereby making spinal stenosis appear more severe than myelography/myeloCT $[13,14]$. 
TABLE 2: Myelographies in the authors' institution by region and referring department: comparison between 1999 and 2009.

\begin{tabular}{lccccc}
\hline 1999 & Neurosurgery & Neurology & Orthopedics & Others & Total \\
\hline Cervical & 45 & 44 & 1 & 28 & 118 \\
Lumbar & 160 & 26 & 40 & 56 & 282 \\
\hline Total. & & & Orthopedics & Others & T00 \\
\hline 2009 & Neurosurgery & Neurology & 3 & 9 & 6 \\
\hline Cervical & 23 & 8 & 66 & 63 \\
Lumbar & 50 & 6 & & & 128 \\
\hline Total. & & & & $\mathbf{1 7 1}$ \\
\hline
\end{tabular}

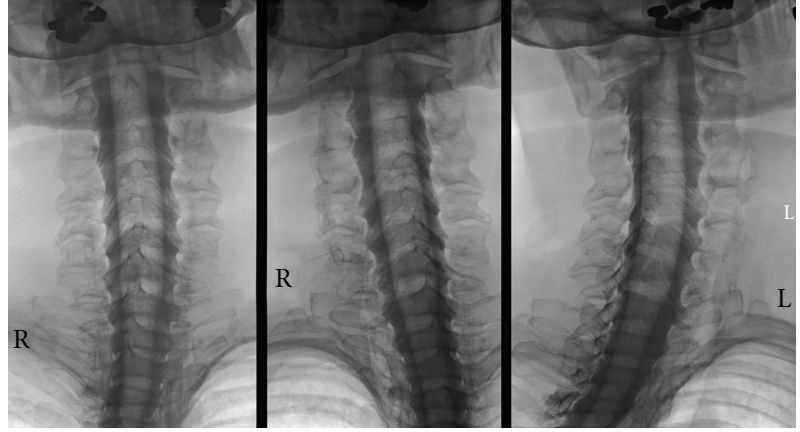

Figure 5: Cervical myelography (prone position). With the patient's head reclined, there is sufficient time to acquire images that show the cervical nerve roots in high detail without losing contrast. (Standard projections as Figure 3).

A special clinical situation that requires detailed highresolution imaging is cervical root avulsion. The typical meningocele is easily identified in any imaging modality, but an older study [15] indicates that myelography is superior to MRI in delineating the ventral and dorsal rootlets with an accuracy of $85 \%$ for CT myelography compared to $58 \%$ for MRI in relation to intraoperative findings. More recent studies reported an accuracy of $88 \%$ for MRI [16] and a sensitivity of $100 \%$ for CT with coronal and oblique coronal reformatted views [17] so that further studies will be necessary to definitely decide which method is the most appropriate in this setting. We mostly use combined myelography and myelo-CT with good results (Figure 7).

A condition that has recently gained some attention is chronic intracranial subdural hematoma due to a spinal CSF leak. Case reports $[18,19]$ show that MR imaging is clearly inferior to myelography in locating the location of the leak. We have made the same experience in some cases; the possibility to dynamically visualize and record the contrast flow makes myelography the method of choice in these cases (Figure 8).

\section{Conclusion and Perspective}

Myelography is no longer the gold standard in the diagnosis of disc herniation and root compression. It is, however, more than just a makeshift when MRI is not possible; myelography

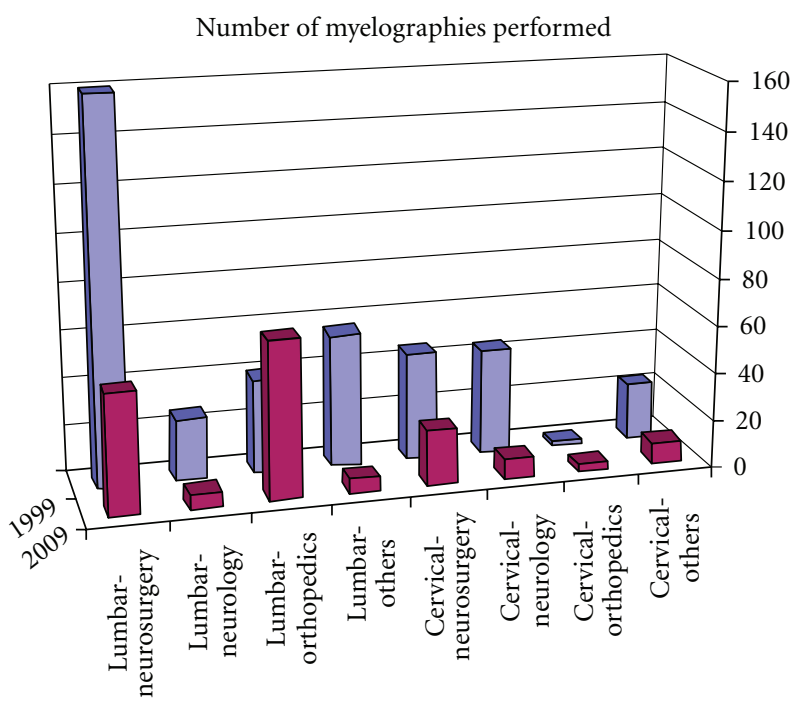

Region and referring department

2009

1999

FIgure 6: Development of myelography exams at the authors' institution 1999-2009.

can provide valuable diagnostic information beyond MRI: the option to acquire dynamic imaging sequences, including positional changes of the patient, and the combination with CT that delivers undistorted images-even with metallic implants - with high spatial and contrast resolution ensure that myelography will remain in the portfolio of neuroradiologic diagnostic tools.

The recently introduced technique of "positional MRI" that allows to examine patients in an upright position including functional (flexion, extension, rotation) views in a vertical-bore low-field MR scanner [20,21] has not gained widespread acceptance yet; the future will show whether this technique can actually replace functional myelography.

As myelography is on the way to become a "special procedure" for selected cases, it becomes even more important that neuroradiologists world-wide make sure that training in myelography remains included in residents' curricula so that experience with this procedure remains available for the next generation of physicians. 


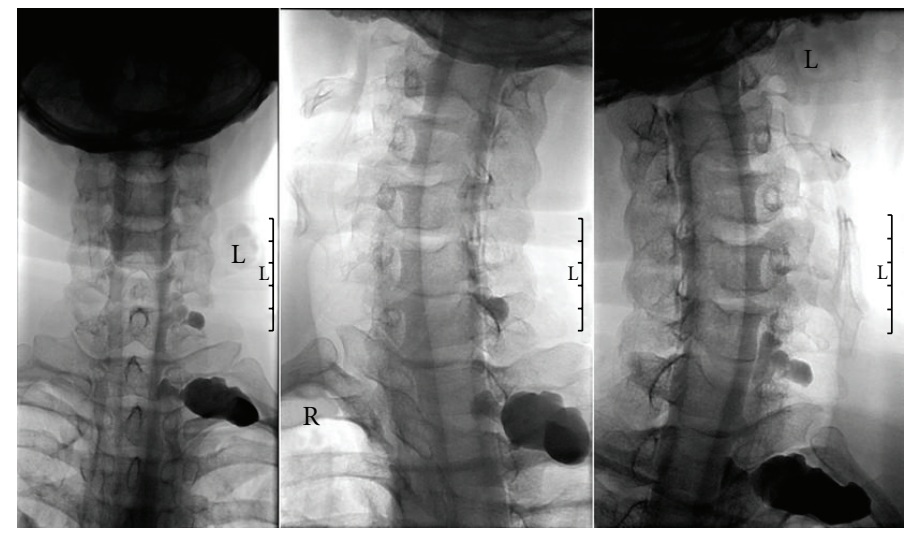

(a)

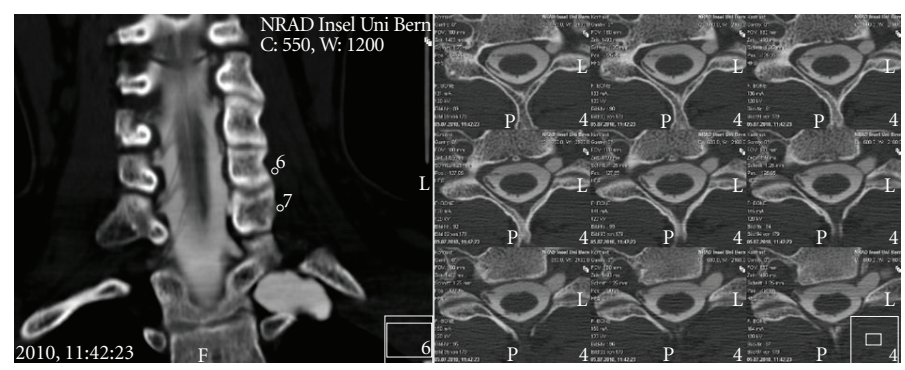

(b)

Figure 7: Cervical root avulsion after motorcycle accident. (a) Myelography shows traumatic pseudoceles C7-D1. Rootlets are not discernible. (b) Thin-section $(1.25 \mathrm{~mm})$ myelo-CT and reformatted coronal images clearly show complete avulsion of ventral and dorsal rootlets.

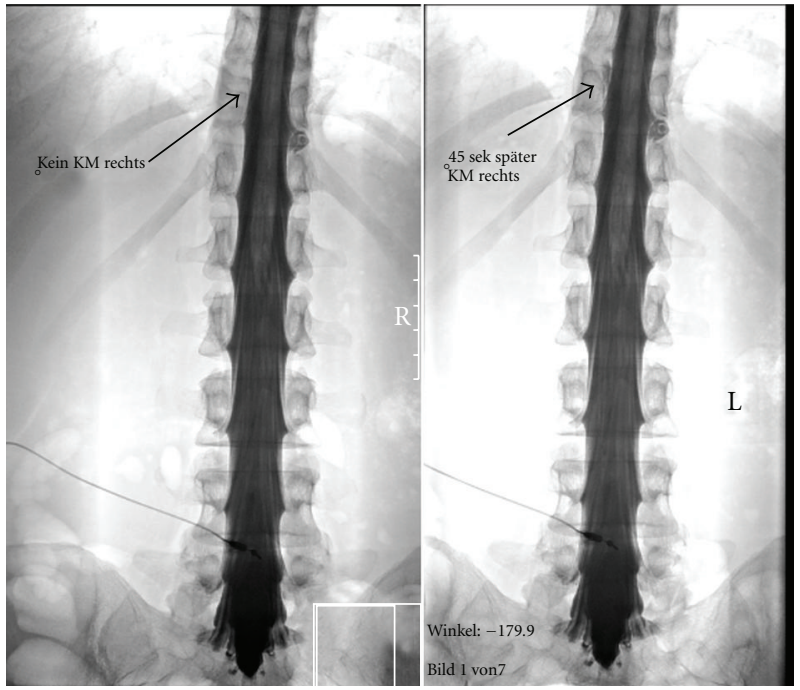

(a)

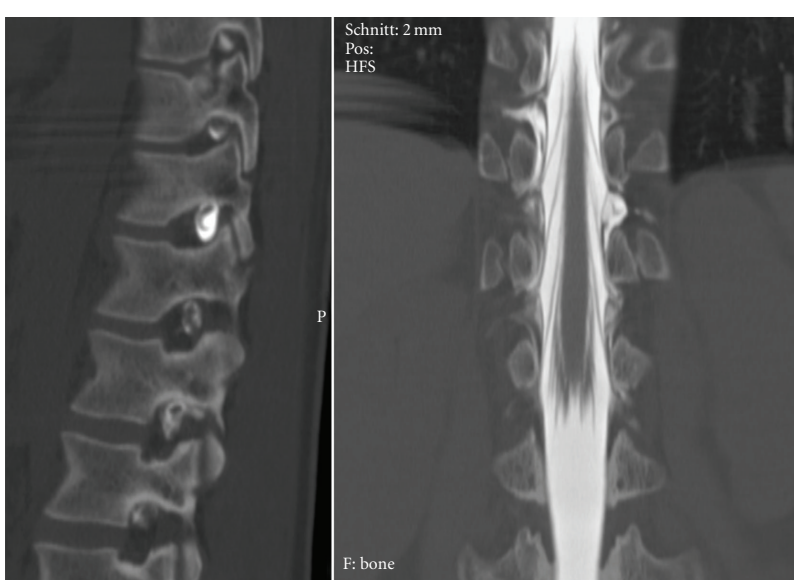

(b)

FIGURE 8: Spinal CSF leak causing subdural hematoma. (a) Left: contrast leakage to the left at the level of the D11 root. Right: 45 seconds later, contrast has flown around the dural sac and is exiting the spinal canal to the right. The dynamic series easily allows to study these flow dynamics and avoids misinterpretations. (b) Sagittal (left) and coronal (right) reformatted images from the subsequent myelo-CT show leakage in the left D11/12 foramen and contrast leakage to the right one segment above. This static study does not allow to exactly determine how contrast flows in and around the dural sac. 


\section{References}

[1] J. A. Sicard and J. Forestier, "Méthode radiologique d'exploration de la cavité épidurale par le lipiodol," Revista de Neurología, vol. 28, pp. 1264-1266, 1921.

[2] B. Bonnemain, "L'huile iodée (lipiodol) en radiologie. Les premières années d'expérience: 1921-1931," Revue d"Histoire de la Pharmacie, vol. 88, pp. 493-508, 2000.

[3] H. M. Worth, "The use of lipiodol in the localisation of spinal tumours," British Journal of Rheumatology, vol. 11, pp. 211226, 1938.

[4] J. M. Taveras, "Neuroradiology: past, present, future," Radiology, vol. 175, no. 3, pp. 593-602, 1990.

[5] W. G. Peacher and R. C. L. Robertson, "Pantopaque myelography: results, comparison of contrast media, and spinal fluid reaction," Journal of Neurosurgery, vol. 2, pp. 220-231, 1945.

[6] B. B. Whitcomb and G. M. Wyatt, "Technique of pantopaque myelography," Journal of Neurosurgery, vol. 3, pp. 95-99, 1946.

[7] G. Di Chiro and D. Schellinger, "Computed tomography of spinal cord after lumbar intrathecal introduction of metrizamide (computer assisted myelography)," Radiology, vol. 120, no. 1, pp. 101-104, 1976.

[8] B. A. Sandow and J. F. Donnal, "Myelography complications and current practice patterns," American Journal of Roentgenology, vol. 185, no. 3, pp. 768-771, 2005.

[9] ACR Guidelines and Standards Committee and ASNR Guidelines Committee: Practice Guideline for the Performance of Myelography and Cisternography (amended 2009), http://www.acr.org/SecondaryMainMenuCategories/quality_ safety/guidelines/dx/head-neck/myelography.aspx.

[10] W. S. Bartynski and L. Lin, "Lumbar root compression in the lateral recess: MR imaging, conventional myelography, and CT myelography comparison with surgical confirmation," American Journal of Neuroradiology, vol. 24, no. 3, pp. 348360, 2003.

[11] E. S. Moon, H. S. Kim, J. O. Park et al., "Comparison of the predictive value of myelography, computed tomography and MRI on the treadmill test in lumbar spinal stenosis," Yonsei Medical Journal, vol. 46, no. 6, pp. 806-811, 2005.

[12] M. Morita, A. Miyauchi, S. Okuda, T. Oda, and M. Iwasaki, "Comparison between MRI and myelography in lumbar spinal canal stenosis for the decision of levels of decompression surgery," Journal of Spinal Disorders \& Techniques, vol. 24, no. 1, pp. 31-36, 2011.

[13] A. E. Grams, J. Gempt, and A. Förschler, "Comparison of spinal anatomy between 3-Tesla MRI and CT-myelography under healthy and pathological conditions," Surgical and Radiologic Anatomy, vol. 32, no. 6, pp. 581-585, 2010.

[14] T. Naganawa, K. Miyamoto, H. Ogura, N. Suzuki, and K. Shimizu, "Comparison of magnetic resonance imaging and computed tomogram-myelography for evaluation of cross sections of cervical spinal morphology," Spine, vol. 36, no. 1, pp. 50-56, 2011.

[15] G. A. Carvalho, G. Nikkhah, C. Matthies, G. Penkert, and M. Samii, "Diagnosis of root avulsions in traumatic brachial plexus injuries: value of computerized tomography myelography and magnetic resonance imaging," Journal of Neurosurgery, vol. 86, no. 1, pp. 69-76, 1997.

[16] K. Abul-Kasim, C. Backman, A. Björkman, and L. B. Dahlin, "Advanced radiological work-up as an adjunct to decision in early reconstructive surgery in brachial plexus injuries," Journal of Brachial Plexus and Peripheral Nerve Injury, vol. 5, no. 1, pp. 14-20, 2010.
[17] H. Yamazaki, K. Doi, Y. Hattori, and S. Sakamoto, "Computerized tomography myelography with coronal and oblique coronal view for diagnosis of nerve root avulsion in brachial plexus injury," Journal of Brachial Plexus and Peripheral Nerve Injury, vol. 2, no. 1, article 16, 2007.

[18] A. Buvanendran, R. W. Byrne, M. Kari, and J. S. Kroin, "Occult cervical (C1-2) dural tear causing bilateral recurrent subdural hematomas and repaired with cervical epidural blood patch: case report," Journal of Neurosurgery: Spine, vol. 9, no. 5, pp. 483-487, 2008.

[19] J. Mizuno, P. V. Mummaneni, G. E. Rodts, and D. L. Barrow, "Recurrent subdural hematoma caused by cerebrospinal fluid leakage: case report," Journal of Neurosurgery: Spine, vol. 4, no. 2, pp. 183-185, 2006.

[20] D. Weishaupt, M. R. Schmid, M. Zanetti et al., "Positional MR imaging of the lumbar spine: does it demonstrate nerve root compromise not visible at conventional MR imaging?" Radiology, vol. 215, no. 1, pp. 247-253, 2000.

[21] F. Alyas, D. Connell, and A. Saifuddin, "Upright positional MRI of the lumbar spine," Clinical Radiology, vol. 63, no. 9, pp. 1035-1048, 2008. 


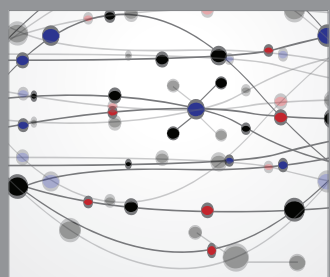

The Scientific World Journal
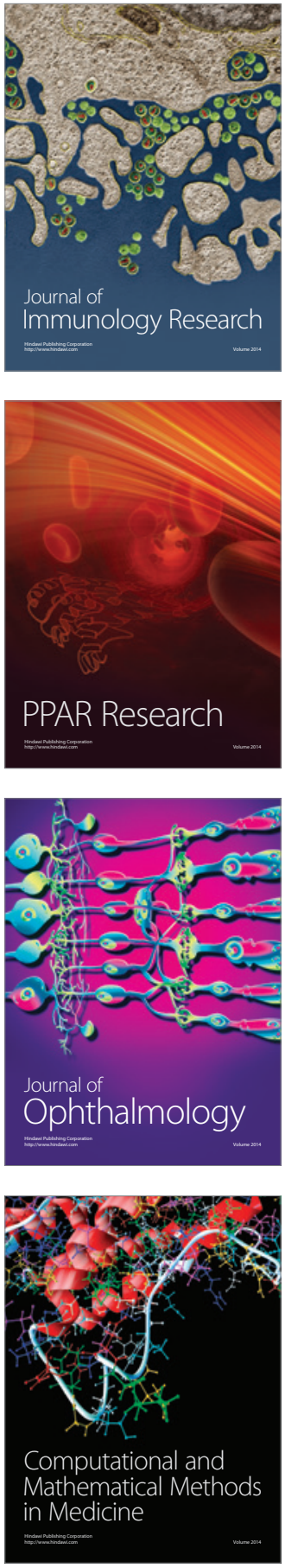

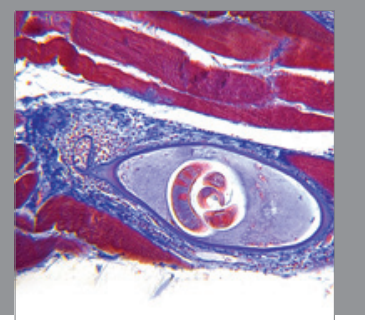

Gastroenterology

Research and Practice
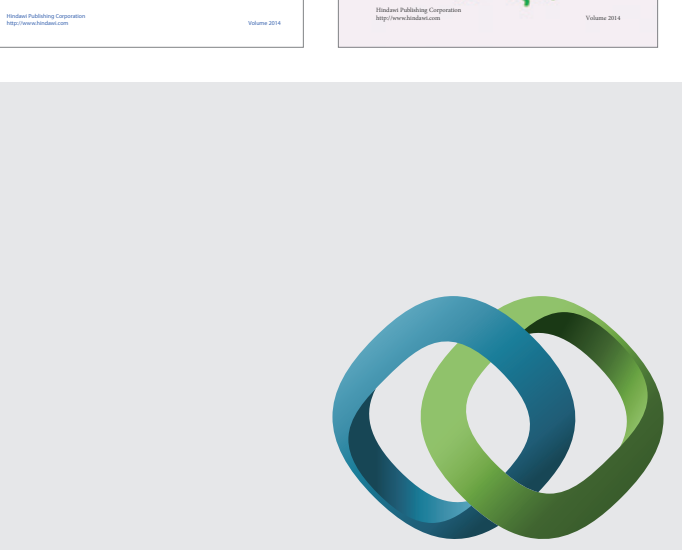

\section{Hindawi}

Submit your manuscripts at

http://www.hindawi.com
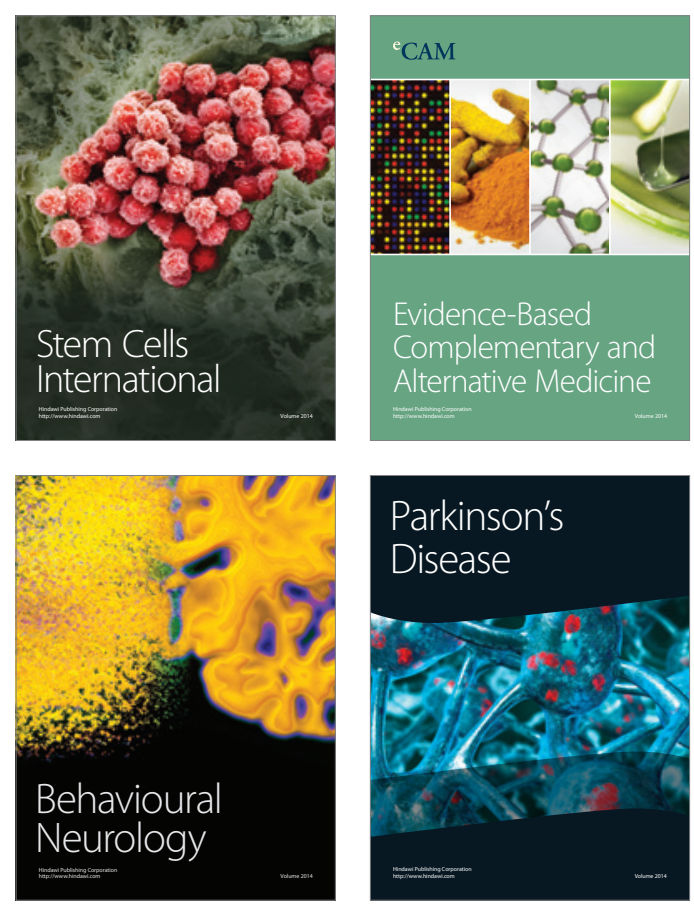

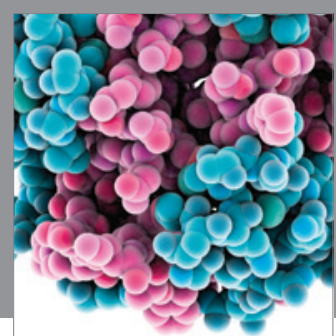

Journal of
Diabetes Research

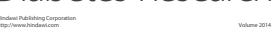

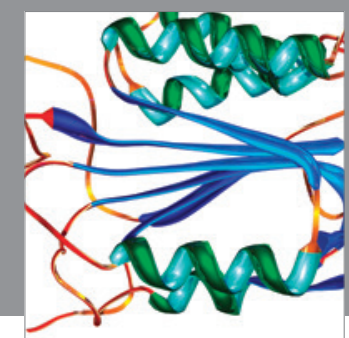

Disease Markers
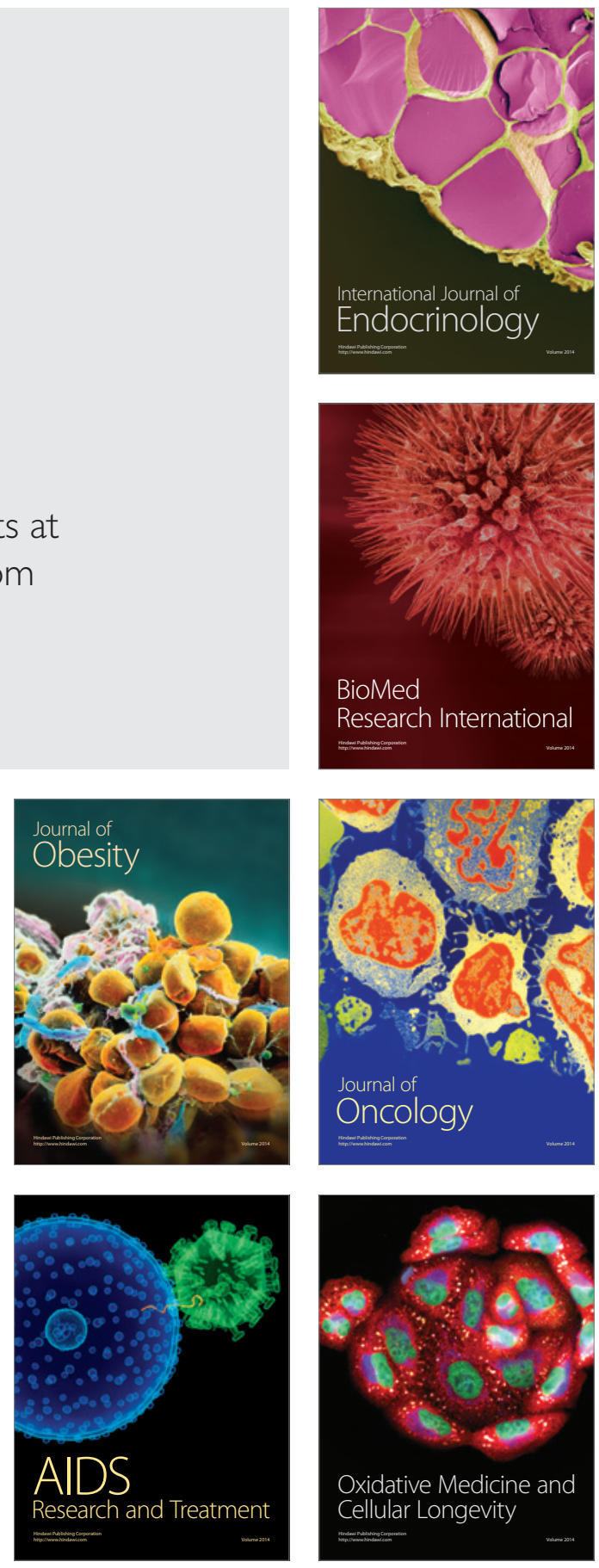